\title{
No Dose Response Relationship in the Effects of Commonly Consumed Sugars on Risk Factors for Diabetes across a Range of Typical Human Consumption Levels
}

\author{
Joshua Lowndes', Diana Kawiecki' ${ }^{1}$, Zhiping Yu², James M. Rippe ${ }^{3,4^{*}}$ \\ ${ }^{1}$ Rippe Lifestyle Institute, Celebration, USA \\ ${ }^{2}$ Department of Nutrition and Dietetics, University of North Florida, Jacksonville, USA \\ ${ }^{3}$ Rippe Lifestyle Institute, Shrewsbury, USA \\ ${ }^{4}$ Department of Biomedical Sciences, University of Central Florida, Orlando, USA \\ Email: jlowndes@rippelifestyle.com, zhiping.nutrition@gmail.com, ${ }^{*}$ jirippe@rippelifestyle.com
}

Received 29 December 2014; accepted 8 January 2015; published 13 January 2015

Copyright (C) 2015 by authors and Scientific Research Publishing Inc.

This work is licensed under the Creative Commons Attribution International License (CC BY).

http://creativecommons.org/licenses/by/4.0/

(c) (i) 0pen Access

\section{Abstract}

Questions have been raised as to whether dietary carbohydrate intake is directly related to the development of type 2 diabetes. Of particular importance, fructose-induced insulin resistance has been previously shown in animals. However, the implications of such findings for humans are unclear as these models typically use very high doses of sugars and from sources not commonly consumed. Little is known about how the typical consumption of sugar in humans affects risk factors for diabetes. 355 weight-stable (weight change $<3 \%$ in previous 30 days) individuals aged 20 - 60 years old drank sugar-sweetened low fat milk every day for 10 weeks as part of their usual diet. Added sugar was provided in the milk as either high fructose corn syrup or sucrose at $8 \%, 18 \%$ or $30 \%$ of the calories required to maintain body weight. Insulin resistance was measured using the Homeostasis Model Assessment (HOMA IR) on fasting measures and a standard Oral Glucose Tolerance Test (OGTT) was used to measure insulin and glucose areas under the curve resistance (AUC30 $\mathrm{g} *$ AUC30 I) and whole body insulin sensitivity and hepatic insulin resistance using the Matsuda Composite Insulin Sensitivity Index (ISI). There was a small increase in weight in the entire cohort $(169.1 \pm 30.6$ vs $171.6 \pm 31.8 \mathrm{lbs}, \mathrm{p}<0.001)$, which was greater in the $30 \%$ level than in the $8 \%$ or $18 \%$ levels ( $<$ <.05). Glucose, insulin, HOMA, glucose AUC, insulin AUC, Matsuda insulin sensitivity index, and hepatic insulin resistance did not vary by sugar level $(p>0.05)$ nor by sugar type $(p>0.05)$. In the entire cohort insulin sensitivity decreased as evidenced by an increase in HOMA IR (1.8 \pm 1.3 vs $2.3 \pm 3.4, p<0.01)$ and a decrease in the Matsuda ISI $(13.1 \pm 21.3$ vs $11.6 \pm$ $16.1, p<0.05)$. Hepatic insulin resistance was unchanged $(2.4 \pm 1.7$ vs $2.4 \pm 1.7 p>0.05)$. Neither

\footnotetext{
${ }^{*}$ Corresponding author.
}

How to cite this paper: Lowndes, J., Kawiecki, D., Yu, Z.P. and Rippe, J.M. (2015) No Dose Response Relationship in the Effects of Commonly Consumed Sugars on Risk Factors for Diabetes across a Range of Typical Human Consumption Levels. Food and Nutrition Sciences, 6, 101-111. http://dx.doi.org/10.4236/fns.2015.61011 
sugar level nor sugar type had any effect on any of these three measures (interaction $p>0.05$ ). These data show that risk factors for diabetes do not vary between the $8 \%$ ( $25^{\text {th }}$ percentile), and the $30 \%$ group $\left(95^{\text {th }}\right.$ percentile) although insulin sensitivity may be affected by sugar consumption across a wide range of typical consumption levels. Importantly, the type of sugar (HFCS versus sucrose) had no effect on any response.

\section{Keywords}

\section{High Fructose Corn Syrup, Sucrose, Diabetes}

\section{Introduction}

Type 2 diabetes has increased dramatically worldwide in the past 20 years and represents a major global public health concern [1]. It has been estimated that $6.4 \%$ of the world population is currently diabetic and this estimate rises to $7.7 \%$ worldwide by the year 2030 [2]. A recent report demonstrated that the number of people with diabetes rose worldwide from 153 million in 1980 to 347 million in 2008 [3]. The International Diabetes Federation has estimated that the number of people affected by diabetes will grow to 438 million by 2030 [4]. While diabetes is a significant problem in the developed world, these increases are anticipated to effect developing countries disproportionately with an estimated $20 \%$ increase in diabetic adults in developed countries compared with an estimated $69 \%$ increase in the number of diabetic adults in developing countries [2].

The increased prevalence of diabetes has led to substantial increases in high blood pressure, stroke, heart disease, kidney disease, and risk of breast, colon and other cancers. These problems will become more prevalent as the diabetes epidemic continues to grow. The increased prevalence of diabetes has been clearly linked to worldwide increases in obesity which has led scientists to explore a variety of dietary factors in the etiology of these related conditions [5]-[8].

Recently considerable attention has been focused on consumption of fructose containing sugars including fructose itself, high fructose corn syrup (HFCS), sucrose and their possible role in promoting Type 2 diabetes [5]-[15]. Several epidemiologic studies have linked consumption of sugar sweetened beverages (SSBs) to increased risk of diabetes [5]-[8]. Two recent ecologic studies have linked the rise in fructose availability (either from HFCS or sucrose) to increased prevalence of obesity both in the United States and around the world [14] [15]. Animal studies [16]-[21], and acute human trials [7] [22], particularly those over feeding fructose beyond normal population intakes, have also supported this association. However, higher quality evidence from prospective cohort studies, systematic reviews and meta-analyses, as well as randomized controlled trials have generally not supported the link between fructose alone or fructose containing sugars and the development of Type 2 diabetes [23]-[28].

Several organizations have recommended different upper limits of consumption of fructose based on concerns about the relationship of fructose containing sugars to various medical conditions and diseases such as obesity, coronary heart disease (CHD), the metabolic syndrome, non-alcoholic fatty liver disease (NAFLD) and diabetes. The American Heart Association (AHA), for example, has published guidelines recommending that American men consume no more than 150 kcals per day in added sugars and American women no more than 100 kcals per day in added sugars [29]. This represents between $5 \%$ and $7 \%$ of all calories consumed and is a level currently exceeded by over $90 \%$ of the population in the United States. The World Health Organization (WHO) has recently released guidelines recommending that individuals consume no more than $10 \%$ of calories from added sugars with the ultimate goal of reducing this number to 5\% [30]. The recently released draft of the Scientific Advisory Committee on Nutrition Report in England recommended guidelines similar to WHO [31]. In contrast, the Dietary Guidelines for Americans (DGAs, 2010), recommended an upper limit of no more than 25\% of calories from added sugars [32]. This recommendation was based on the Institute of Medicine (IOM) report on carbohydrates and health [33] which made the same recommendation. Thus, several different guidelines for upper limits of consumption of fructose containing sugars have been proposed.

The study reported here was undertaken to explore the relationship between fructose containing sugars and risk factors for diabetes in the normal range of human consumption between the $25^{\text {th }}$ and $90^{\text {th }}$ percentile popula- 
tion consumption levels for individuals in the United States [30]. We compared 8\% of calories from added sugars (roughly the upper limit recommended by AHA, WHO and draft guidelines from the Scientific Advisory Committee on Nutrition (SACN)) to $18 \%$ of calories (the average fructose consumption level in the United States) [34] and 30\% of calories from added sugars (the $95^{\text {th }}$ percentile population consumption level of fructose in the United States [34] and roughly equivalent to the $25 \%$ of added calories upper limit recommended by the DGAs 2010 and IOM report).

We hypothesized that there would be no increases in risk factors for diabetes including insulin, fasting glucose, insulin resistance, total body insulin sensitivity, or hepatic insulin resistance in the healthy population studied. We further hypothesized that there would be no differences in these parameters when comparing the AHA, WHO and SACN recommendations for upper limits of added sugars to the DGA 2010 and IOM recommendations.

\section{Materials and Methods}

\subsection{Overview}

This study has been previously described (Lowndes et al.) [35]. In summary, this was a randomized, prospective, parallel group, partially blinded study to assess the effects of incorporation of one of three different levels of consumption of one of two different types of sugars into the usual diet. The study had a duration of ten weeks. Participants were blind to both the level of consumption and type of sugar they had been randomly assigned to consume. Research staff were blind to the type of sugar, but it was necessary for them to be aware of the sugar level. The study was approved by the Western Institutional Review Board.

\subsection{Study Population}

The study population included men and women between the ages of 20 and 60 years, with a BMI between 21 and $35 \mathrm{~kg} / \mathrm{m}^{2}$. Participants were recruited from newspaper advertisements, postings on the internet and a database of individuals who had participated in previous studies in our research laboratory who had indicated a desire to participate in further research trials. All participants were weight stable (no change in weight greater than $3 \%$ in the past month, no actions taken in 3 months to lose weight), non-smokers (not been a regular smoker for at least 12 months and no social smoking for at least 3 months) and normoglycemic (fasting or after a 2 hour oral glucose challenge). Participants were excluded if they had uncontrolled blood pressure, a history of thyroid disease, cancer, gastrointestinal disorders, cardiac problems, eating disorders, if they had ever had a surgical procedure for weight loss, if they had undergone any major surgical procedure in the previous 3 months, if they started a new medication within the past 3 months (including a change in dose of an existing medication), if they were pregnant or lactating, if they consumed more than 3 alcoholic drinks per week or if they had any significant food allergy. Additionally, participants were not allowed to enroll if they had participated in any other clinical trial within the previous 30 days. All participants provided signed informed consent.

\subsection{Intervention}

Participants were required to consume sugar-sweetened, low-fat milk daily as part of their usual diet for the ten week duration of the intervention. The number of calories required for weight maintenance was estimated for each participant (via Mifflin St. Jeor prediction equation [36] and the level of milk consumption was calculated so that the added sugar contributed a target percentage of that weight-maintenance caloric intake. Participants were randomly assigned to a target consumption level of $8 \%, 18 \%$ or $30 \%$, and also to consume milk sweetened with either sucrose or HFCS. Participants had unlimited flexibility in the makeup of the remainder of their diet, but were instructed on the need to account for the calories from the milk if they wanted to maintain their initial body mass. Participants were instructed to eat to the same level of "fullness".

A week's supply of milk was allocated to each participant upon completion of the pre-testing phase. Participants were then required to return to the clinic for weekly visits so that body weight could be measured, to have dietary logs and compliance checklist reviewed and to be provided with another week's supply of milk.

\subsection{Oral Glucose Tolerance Test and Blood Plasma Measurements}

A standard two hour Oral Glucose Tolerance Test (OGTT) was performed during pre-testing and again after 
completion of the ten week intervention. Prior to consumption of the 75 g glucose solution, an IV was inserted and a blood sample was obtained for the measurement of fasting glucose and insulin. Participants were then given the glucose solution and allowed 5 minutes to consume it. Additional blood samples were then obtained after 30, 60, 90 and 120 minutes. At all time points blood was collected in BD vacutainers containing ethylenediaminetetraacetic acid (EDTA) for the preparation of plasma. Aliquots from collected samples were obtained and divided into two. The first aliquot was used immediately to test plasma using the YSI 2300 analyzer. The remaining aliquot was stored at $-80^{\circ} \mathrm{C}$ for future batch testing of insulin. This was performed via ELISA with kits EZHI-14K from EMD Millipore (Darmstadt, Germany).

\subsection{Derived Measurements}

Various measures of glucose homeostasis were derived from the fasting values of glucose and insulin, and from values at various time points during the OGTT. Homeostasis Model Assessment of Insulin Resistance was calculated from the fasting insulin and glucose measurements-((Glucose * Insulin)/22.5) [37]. 2 hour area under the curve (AUC) values were calculated for glucose and insulin using the standard trapezoidal method. Hepatic insulin resistance was measured as the product of glucose and insulin values at 30 minutes of the OGTT, a procedure validated against clamp methods [38]. Whole body insulin sensitivity and hepatic insulin resistance were calculated from samples obtained during the OGTT using the Matsuda Index [39],

$$
\frac{1000}{\sqrt{g_{0} \times i_{0} \times \frac{\left(g_{0} \cdot 15+g_{30} \cdot 30+g_{60} \cdot 30+g_{90} \cdot 30+g_{120} \cdot 15\right)}{120} \times \frac{\left(i_{0} \cdot 15+i_{30} \cdot 30+i_{60} \cdot 30+i_{90} \cdot 30+i_{120} \cdot 15\right)}{120}}} .
$$

\subsection{Statistical Analyses}

All data are presented as means \pm standard deviation (SD) and analyzed using SPSS-PASW Statistics (version 18.0). Outcome measures were analyzed via a 2 (sugar type) $\times 3$ (sugar level) way ANOVA with repeated measures (2 time points). Significant interactions for sugar level were probed by via one way Tukey's post hoc. Statistical significance was defined by $\mathrm{p}<0.05$.

\section{Results}

\subsection{Demographic Information}

Both demographic information and participant retention have been previously described in this cohort (Lowndes et al.). In short, 465 participants successfully completed the pre-testing procedures without getting disqualified. Of those, 355 completed the intervention (male $=165$, female $=190 ; 26 \%$ drop outs) and are described in Table 1. Both pre and post-intervention OGTTs were completed on 236 of these participants.

\subsection{Body Weight}

As previously reported [35], there was a small increase in weight in the entire cohort of sugar sweetened, low-fat milk drinker (169.1 \pm 30.6 vs $171.6 \pm 31.8 \mathrm{lbs}, \mathrm{p}<0.001)$. The increase was greater $(\mathrm{p}<0.05)$ in the $30 \%$ group ( $3.7 \pm 5.0 \mathrm{lbs})$ than in the $8 \%(2.1 \pm 5.0 \mathrm{lbs})$ and $18 \%$ groups $(1.9 \pm 5.3 \mathrm{lbs})$. However, the type of sugar consumed had no effect on body weight.

\subsection{Fasting Measures}

Fasting glucose was unchanged after ten weeks. Fasting insulin was unchanged in any group (time $\times$ sugar level $\mathrm{p}>0.05)$. HOMA, glucose AUC, insulin AUC, Matsuda insulin sensitivity index and hepatic insulin resistance did not vary by sugar level $(p>0.05)$ nor by sugar type $(p>0.05)$. However, fasting insulin did increase in the entire pooled cohort of sugar sweetened, low-fat milk drinkers ( $7.9 \pm 5.4$ vs $10.1 \pm 12.8 \mu \mathrm{IU} / \mathrm{ml}, \mathrm{p}<0.01)$ and this produced an increase in insulin resistance as measured by HOMA $(1.8 \pm 1.3$ vs $2.3 \pm 3.4$, p $<0.01)$. This was unaffected by the type of sugar consumed, the level of consumption, or any combination of the two factors. These data are presented in Table 2. 
Table 1. Baseline characteristics of 355 participants who completed the intervention.

\begin{tabular}{|c|c|c|c|c|c|c|c|}
\hline & $\begin{array}{c}\text { Total } \\
(\mathrm{n}=355) ; \\
\mathrm{M}=165, \mathrm{~F}=190\end{array}$ & $\begin{array}{c}8 \% \text { sucrose } \\
(n=58) \\
M=32, F=26\end{array}$ & $\begin{array}{c}8 \% \text { HFCS } \\
(n=69) \\
M=27, F=42\end{array}$ & $\begin{array}{c}18 \% \text { HFCS } \\
(n=60) \\
M=30, F=30\end{array}$ & $\begin{array}{c}18 \% \text { sucrose } \\
(n=64) \\
M=26 F=38\end{array}$ & $\begin{array}{c}30 \% \text { HFCS } \\
(n=51) \\
M=23, F=28\end{array}$ & $\begin{array}{c}30 \% \text { sucrose } \\
(n=53) \\
M=27, F=26\end{array}$ \\
\hline Age (years) & $40.19 \pm 11.59$ & $38.62 \pm 12.33$ & $38.93 \pm 11.65$ & $40.43 \pm 11.33$ & $41.30 \pm 11.10$ & $43.41 \pm 11.33$ & $38.85 \pm 11.56$ \\
\hline Weight (lbs) & $169.11 \pm 30.64$ & $175.58 \pm 32.93$ & $168.63 \pm 31.19$ & $168.42 \pm 30.35$ & $165.85 \pm 30.50$ & $172.73 \pm 27.58$ & $163.90 \pm 30.46$ \\
\hline BMI & $26.99 \pm 3.57$ & $27.55 \pm 3.94$ & $27.06 \pm 3.73$ & $27.06 \pm 3.51$ & $26.25 \pm 3.06$ & $27.91 \pm 3.69$ & $26.19 \pm 3.27$ \\
\hline SBP (mmHg) & $109.42 \pm 10.91$ & $111.02 \pm 11.22$ & $107.65 \pm 10.90$ & $108.37 \pm 9.51$ & $107.64 \pm 11.06$ & $112.35 \pm 11.28$ & $110.43 \pm 11.04$ \\
\hline DBP (mmHg) & $72.18 \pm 7.97$ & $72.00 \pm 8.01$ & $71.64 \pm 6.71$ & $72.15 \pm 7.74$ & $70.70 \pm 8.87$ & $74.66 \pm 8.19$ & $72.54 \pm 8.09$ \\
\hline Glucose (mg/dl) & $89.49 \pm 6.42$ & $90.83 \pm 6.15$ & $89.39 \pm 6.15$ & $89.56 \pm 6.08$ & $88.52 \pm 6.63$ & $90.00 \pm 6.74$ & $88.77 \pm 6.85$ \\
\hline
\end{tabular}

HFCS = high fructose corn syrup. Beverages included HFCS or Sucrose sweetened low fat milk to provide $8 \%, 18 \%$ or $30 \%$ of calories from added sugar.

Table 2. Fasting measurements obtained prior to and after ten weeks of daily consumption of sugar sweetened milk.

\begin{tabular}{|c|c|c|c|c|c|c|c|c|c|c|c|c|}
\hline & & $8 \%$ HFCS & $8 \%$ sucrose & $18 \%$ HFCS & $18 \%$ sucrose & $30 \%$ HFCS & $30 \%$ sucrose & All & Time & $\begin{array}{c}\text { Time } \times \\
\text { sugar } \\
\text { type }\end{array}$ & $\begin{array}{l}\text { Time } \times \\
\text { sugar } \\
\text { level }\end{array}$ & $\begin{array}{l}\text { Time } \times \text { sugar } \\
\text { type } \times \text { level }\end{array}$ \\
\hline $\begin{array}{c}\text { Weight } \\
\text { (lbs) }\end{array}$ & $\begin{array}{l}\text { Pre } \\
\text { Post }\end{array}$ & $\begin{array}{l}168.6 \pm 31.2 \\
170.5 \pm 32.5\end{array}$ & $\begin{array}{l}175.6 \pm 32.9 \\
178.0 \pm 34.1\end{array}$ & $\begin{array}{l}168.4 \pm 30.4 \\
169.9 \pm 30.6\end{array}$ & $\begin{array}{l}165.8 \pm 30.5 \\
168.2 \pm 32.7\end{array}$ & $\begin{array}{l}172.7 \pm 27.6 \\
175.8 \pm 28.8\end{array}$ & $\begin{array}{l}163.9 \pm 30.5 \\
168.2 \pm 31.4\end{array}$ & $\begin{array}{l}169.1 \pm 30.6 \\
171.6 \pm 31.8\end{array}$ & $<0.001$ & 0.114 & 0.018 & 0.855 \\
\hline $\begin{array}{l}\text { Glucose } \\
\text { (mg/dl) }\end{array}$ & $\begin{array}{l}\text { Pre } \\
\text { Post }\end{array}$ & $\begin{array}{l}89.1 \pm 6.0 \\
87.9 \pm 9.8\end{array}$ & $\begin{array}{l}90.9 \pm 6.3 \\
91.4 \pm 9.6\end{array}$ & $\begin{array}{l}89.6 \pm 6.1 \\
90.6 \pm 7.7\end{array}$ & $\begin{array}{l}88.4 \pm 6.6 \\
88.8 \pm 7.7\end{array}$ & $\begin{array}{l}89.6 \pm 6.7 \\
91.7 \pm 6.7\end{array}$ & $\begin{array}{l}88.8 \pm 6.8 \\
90.2 \pm 8.1\end{array}$ & $\begin{array}{l}89.4 \pm 6.4 \\
90.0 \pm 8.5\end{array}$ & 0.104 & 0.878 & 0.166 & 0.403 \\
\hline $\begin{array}{c}\text { Insulin } \\
(\mu \mathrm{IU} / \mathrm{ml})\end{array}$ & $\begin{array}{l}\text { Pre } \\
\text { Post }\end{array}$ & $8.6 \pm 5.9$ & $8.2 \pm 4.9$ & $\begin{array}{l}7.9 \pm 5.7 \\
7.5 \pm 5.5\end{array}$ & $7.3 \pm 5.8$ & $8.3 \pm 4.5$ & $6.9 \pm 5.0$ & $\begin{array}{c}7.9 \pm 5.4 \\
10.1 \pm 12.8\end{array}$ & 0.001 & 0.406 & 0.139 & 0.147 \\
\hline HOMA & $\begin{array}{l}\text { Pre } \\
\text { Post }\end{array}$ & $\begin{array}{l}1.9 \pm 1.4 \\
2.1 \pm 1.6\end{array}$ & $\begin{array}{l}1.9 \pm 1.2 \\
3.2 \pm 6.0\end{array}$ & $\begin{array}{l}1.8 \pm 1.3 \\
1.7 \pm 1.3\end{array}$ & $\begin{array}{l}1.6 \pm 1.3 \\
1.8 \pm 1.5\end{array}$ & $\begin{array}{l}1.9 \pm 1.1 \\
3.1 \pm 5.0\end{array}$ & $\begin{array}{l}1.5 \pm 1.2 \\
2.1 \pm 1.9\end{array}$ & $\begin{array}{l}1.8 \pm 1.3 \\
2.3 \pm 3.4\end{array}$ & 0.003 & 0.483 & 0.189 & 1.139 \\
\hline
\end{tabular}

Note: Participants consumed milk in amounts necessary so that the added sugar provided $8 \%$, $18 \%$ or $30 \%$ of the calories needed to maintain body weight. HOMA IR = Homeostasis Model Assessment of Insulin Resistance.

\subsection{Oral Glucose Tolerance Test}

Data obtained from the OGTTs are presented in Table 3. There were no changes in 2 hour AUCs for either glucose or for insulin. The product of glucose and insulin values at 30 minutes, a validated measure of hepatic insulin resistance, was also unchanged. Consistent with an increase in HOMA IR, insulin sensitivity, as measured by the Matsuda Index, decreased in the entire pool study population $(13.1 \pm 21.3$ vs $11.6 \pm 16.1, \mathrm{p}<0.05)$. These effects were not different across the range of consumptions levels and between the type of sugars consumed.

\section{Discussion}

The results of this study confirmed our hypothesis that fructose containing sugars when consumed over a ten week period at dosage ranges between the $25^{\text {th }}$ and $95^{\text {th }}$ percentile population consumption level for fructose did not result in increased risk factors for diabetes.

These findings are consistent with the findings of Cozma et al. who performed a systematic review and metaanalysis of an 18 trials of isocaloric exchange of fructose for other sources of carbohydrate and found that fructose consumption did not significantly affect fasting glucose or insulin and led to a reduction in hemoglobin A1C [27].

Our findings are at variance with results reported by Stanhope et al. [22] and a second study by Le et al. [7] which reported increases in insulin resistance utilizing different conditions than were employed in the current study. In the Stanhope et al. study, the effects of $25 \%$ of calories from fructose were compared to $25 \%$ of calories from glucose. In the group which consumed $25 \%$ of calories from fructose, increases in hepatic fat content, 
Table 3. Measures of glucose and insulin metabolism derived from a standard 2 hour oral glucose tolerance test performed prior to and after ten weeks of daily consumption of sugar sweetened milk.

\begin{tabular}{|c|c|c|c|c|c|c|c|c|c|c|c|c|}
\hline & & 8\% HFCS & $8 \%$ Sucrose & e $18 \%$ HFCS & $\begin{array}{c}18 \% \\
\text { sucrose }\end{array}$ & $30 \%$ HFCS & $\begin{array}{c}30 \% \\
\text { sucrose }\end{array}$ & All & Time & $\begin{array}{c}\text { Time } \times \\
\text { sugar type }\end{array}$ & $\begin{array}{c}\text { Time } \times \\
\text { sugar level }\end{array}$ & $\begin{array}{c}\text { Time } \times \\
\text { sugar } \\
\text { type } \times \\
\text { level }\end{array}$ \\
\hline $\begin{array}{c}\text { Glucose } \\
\text { AUC } \\
\text { (units) }\end{array}$ & $\begin{array}{l}\text { Pre } \\
\text { Post }\end{array}$ & $\begin{array}{l}13.4 \pm 2.1 \\
13.7 \pm 2.5\end{array}$ & $\begin{array}{l}13.8 \pm 2.3 \\
13.7 \pm 2.6\end{array}$ & $\begin{array}{l}13.4 \pm 2.4 \\
13.7 \pm 2.4\end{array}$ & $\begin{array}{l}13.8 \pm 2.2 \\
13.3 \pm 2.7\end{array}$ & $\begin{array}{l}13.9 \pm 2.9 \\
13.4 \pm 3.2\end{array}$ & $\begin{array}{l}12.9 \pm 2.7 \\
13.1 \pm 2.6\end{array}$ & $\begin{array}{l}13.5 \pm 2.4 \\
13.6 \pm 2.7\end{array}$ & 0.434 & 0.134 & 0.567 & 0.753 \\
\hline $\begin{array}{l}\text { Insulin } \\
\text { (units) }\end{array}$ & $\begin{array}{l}\text { Pre } \\
\text { Post }\end{array}$ & $\begin{array}{l}4.2 \pm 2.7 \\
4.4 \pm 3.0\end{array}$ & $\begin{array}{l}4.3 \pm 2.0 \\
4.7 \pm 2.5\end{array}$ & $\begin{array}{l}4.0 \pm 2.4 \\
3.6 \pm 1.6\end{array}$ & $\begin{array}{l}3.8 \pm 2.4 \\
4.1 \pm 3.3\end{array}$ & $\begin{array}{l}4.2 \pm 2.0 \\
4.7 \pm 2.6\end{array}$ & $\begin{array}{l}3.7 \pm 2.9 \\
3.6 \pm 2.2\end{array}$ & $\begin{array}{l}4.0 \pm 2.4 \\
4.2 \pm 2.6\end{array}$ & 0.234 & 0.629 & 0.641 & 0.143 \\
\hline $\begin{array}{l}\text { Matsuda } \\
\text { insulin } \\
\text { sensitivity } \\
\text { index }\end{array}$ & Post & $\begin{array}{l}12.0 \pm 9.4 \\
10.0 \pm 6.5\end{array}$ & $\begin{array}{l}9.5 \pm 6.5 \\
9.1 \pm 7.1\end{array}$ & $\begin{array}{r}12.2 \pm 13.0 \\
11.9 \pm 8.1\end{array}$ & $\begin{array}{l}19.1 \pm 45.2 \\
16.9 \pm 33.6\end{array}$ & $10.9 \pm 7.1$ & $\begin{array}{l}13.6 \pm 8.3 \\
11.7 \pm 8.3\end{array}$ & $\begin{array}{l}13.1 \pm 21.2 \\
11.6 \pm 16.1\end{array}$ & 0.011 & 0.996 & 0.840 & 0.441 \\
\hline $\begin{array}{l}\text { Hepatic } \\
\text { insulin } \\
\text { resistance }\end{array}$ & Post & $\begin{array}{l}2.4 \pm 1.6 \\
2.4 \pm 1.7\end{array}$ & $\begin{array}{l}2.5 \pm 1.4 \\
2.9 \pm 1.9\end{array}$ & $\begin{array}{l}2.3 \pm 1.6 \\
2.1 \pm 1.2\end{array}$ & $\begin{array}{l}2.6 \pm 2.0 \\
2.5 \pm 2.1\end{array}$ & $\begin{array}{l}2.2 \pm 1.3 \\
2.4 \pm 1.5\end{array}$ & $\begin{array}{l}2.3 \pm 2.1 \\
2.0 \pm 1.1\end{array}$ & $\begin{array}{l}2.4 \pm 1.7 \\
2.4 \pm 1.7\end{array}$ & 0.910 & 0.858 & 0.358 & 0.159 \\
\hline
\end{tabular}

Note: Participants consumed milk in amounts necessary so that the added sugar provided $8 \%, 18 \%$ or $30 \%$ of the calories needed to maintain body weight. AUC $=$ area under the curve. Hepatic insulin resistance $=$ AUC30 glucose $\times$ AUC30 insulin Matsuda insulin sensitivity index $=$ 1000

$\sqrt{g_{0} \times i_{0} \times \frac{\left(g_{0} \cdot 15+g_{30} \cdot 30+g_{60} \cdot 30+g_{90} \cdot 30+g_{120} \cdot 15\right)}{120} \times \frac{\left(i_{0} \cdot 15+i_{30} \cdot 30+i_{60} \cdot 30+i_{90} \cdot 30+i_{120} \cdot 15\right)}{120}}$.

hepatic insulin resistance and total body insulin resistance were reported. It should be pointed out however, that the experimental conditions employed in this study involved very large doses of pure fructose and glucose. Moreover, neither pure fructose nor pure glucose are consumed to any appreciable degree in the human diet. In the Le et al. study [7] a hypercaloric, very high fructose diet (3.5 grams/kg fat-free mass (FFM) per day plus 35\% increase in energy intake) was utilized for 7 days in offspring of individuals of family history of Type 2 diabetes. These dosages are 4 to 5 times the $90^{\text {th }}$ percentile population consumption in the United States of fructose from all sources [34]. These investigators concluded that individuals with a predisposition to diabetes might be more prone to insulin resistance when challenged by very high fructose intakes. As pointed out by White, however, great caution must be used when drawing conclusions based on studies employing such high dosages of fructose, particularly when given in isolation.

Our findings are also consistent with the recent report from the InterAct European Consortium which showed that various digestible carbohydrates including sucrose were not associated with increased risk of Type 2 diabetes in a large prospective, cohort study involving 12,403 individuals with incident Type 2 diabetes compared to a random subcohort of 16,835 individuals [10]. This Inter Act study also showed that neither glycemic index nor glycemic load were associated with increased risk of Type 2 diabetes.

A number of epidemiologic studies have reported intake of sugar sweetened beverages with increased risk of Type 2 diabetes. de Koning et al. demonstrated that participants in the top quartile of sugar-sweetened beverage intake had a $20 \%$ higher relative risk of diabetes than those in the bottom quartile after adjusting for potential confounding factors [8]. Schulze et al. conducted a prospective cohort analysis on the Nurses' Health Study II and demonstrated that higher consumption of sugar sweetened beverages was associated with weight gain and an increased risk of development of Type 2 diabetes in women [6]. These investigators speculated that these increases in risk might come from providing excessive calories in large amounts of rapidly absorbable sugars. Malik et al. performed a meta-analysis on sugar sweetened beverages and weight and concluded that sugar sweetened beverages were associated with weight gain in multiple epidemiologic studies [41]. Montonen et al. studied a cohort of 4304 men and women aged 40 - 60 years old who were free of diabetes at baseline and demonstrated that higher fructose and glucose sweetened beverages increased Type 2 diabetes risk [5] Schulze et al. formed a nested case control study of 656 cases of Type 2 diabetes and 694 controls among the Nurses' Health Study and two prospective cohort studies consisting of 35,340 women in the Nurses' Health Study and 89,311 women in the Nurses' Health Study II and found that a dietary pattern which included sugar sweetened soft drinks, refined grains, diet soft drinks and processed meat, and low in wine, coffee, cruciferous vegetables and 
yellow vegetables was associated with increased risk of diabetes [6].

It should also be pointed out that other epidemiologic studies have shown an association between consumption of red meat [42] as well as potato products [43] and an increased risk of Type 2 diabetes. Thus, whether or not the sugar sweetened beverages per se or even the sugars contained in these beverages are associated with the increased risk of diabetes or are indicative of an overall nutritional pattern which increased the risk of Type 2 diabetes remains to be resolved.

Two recent ecologic studies by Basu et al. [14] and Goran et al. [15] have linked a rise in fructose availability (both from HFCS and sucrose) with an increased risk of diabetes. It should be pointed out, however, that ecological studies are considered a low level of evidence and are limited in their ability to establish an association with certainty due to the potential for residual confounding. In addition, estimates provided are hindered due to the pooling of heterogeneous measurements of exposure and disease incidence.

Furthermore, not all ecological data have shown a positive trend between sugar intake and diabetes rate. For example, in the United States between 1980-2003, while the consumption of total nutritive sweeteners increased, their consumption declined substantially in Australia and the United Kingdom. In Australia, despite a 10\% decrease in the contribution of sugar from SSBs, the prevalence of obesity and diabetes among adults and children increased in line with other Western populations [44]. This has been called the "Australian Paradox" and raises the question of the value of public health interventions based on reducing the consumption of sugar and SSBs as a strategy to reverse the trend of increase in obesity. Interestingly, a similar paradox has also been seen in the United States over the last decade where the prevalence of obesity and diabetes have continued to rise despite reduction in the intake of total added sugars [45] [46].

These findings underscore the important limitations of drawing conclusions about fructose and fructose containing sugars from ecological studies. For example, it may be difficult to separate whether the association seen with fructose is created by excess energy, the colinearity of fructose intake with other dietary or lifestyle factors associated with obesity and diabetes or to potential direct effects of fructose. The findings of the Australian Paradox support the concept that once total energy is accounted for, per capita changes in sweetener availability do not explain the increased incidence of obesity and diabetes. Thus, the inability to account for multiple confounders opens all ecological analyses to the "ecological fallacy" and underscores the need to apply higher level evidence in any potential relationship between added sugars, obesity or diabetes before drawing any conclusions.

Animal models have also been frequently cited for providing evidence of a plausible biologic mechanism for the relationship between fructose containing sugars and obesity, diabetes, and other cardiometabolic diseases. Numerous metabolic differences between animal and human physiology, however, significantly limit the ability to extrapolate these findings to humans. While it has been established that feeding fructose at large doses in animals can create components of the metabolic syndrome including insulin resistance, hypertension, obesity, and dyslipidemia [16]-[21], metabolic differences between animals and humans are particularly relevant in this area. For example, in rodents as much as $60 \%-70 \%$ of total fatty acids may be synthesized through the pathway of de novo lipogenesis (DNL) [20] [21]. However, in human studies this is quantitatively insignificant where de novo lipogenesis contributes less than 5\% of total triglycerides [47]-[49]. In addition, recent reviews of isotope tracer studies in humans have demonstrated that DNL from fructose contributes less than $1 \%$ of total triglyceride synthesis [47] [50]. Conversion to glucose (between 40\% - 45\%) lactate (between 25\% - 30\%) and glycogen (15\% - 20\%) are much more prominent pathways in the metabolism of fructose. Moreover, as White has pointed out in animal studies, fructose is often administered in extremely high doses ( $\geq 60 \%$ of calories which is 5 - 6 times the median population intake of fructose in human beings) [40].

Strengths of the current study include the fact that it was a blinded, randomized, prospective, controlled trial with a large sample size exploring normal population consumption levels of fructose and utilizing the sugars that are typically consumed in the human diet. Weaknesses include that subjects were only followed for 10 weeks and subjects over the age of 60 , children and adolescents, were excluded. Adolescents represent the single highest fructose consuming group in the United States [34].

It should also be noted that HFCS, sucrose, glucose and fructose could not be measured directly in the diets so the actual levels of intake of these sugars remain unknown which should be taken into consideration when interpreting these data. Finally, it should be noted that sugars in this study were delivered in $1 \%$ low fat milk which may represent an additional confounder. 


\section{Conclusions}

In conclusion, the findings from this randomized controlled trial suggest that fructose containing sugars at normal levels of human consumption do not increase risk factors for diabetes. This study contributes to the growing literature that at normal human consumption levels of fructose in eucaloric diets risk factors for diabetes are not increased.

Furthermore, there were no differences for risk factors for diabetes when comparing 8\% of calories from added sugars, a level consistent with the upper limit recommended by the AHA, WHO and draft report of SACN with $18 \%$ of calories (average consumption in the United States) and with $30 \%$, which was comparable to the upper limit recommended by the DGA 2010 and IOM. Our findings suggest that the issue of the appropriate upper limit for added sugar consumption with regard to diabetes is far from being settled.

We wish to emphasize that we are not recommending that individuals consume $25 \%$ or $30 \%$ of calories from added sugars. From a diabetes risk factor perspective, however, we did not detect any differences between this level of added sugar consumption and the more restrictive guidance from AHA, WHO, and SACN with regard to risk factors for diabetes. In addition, this study contributes to the expanding literature that there are no differences between HFCS and sucrose when consumed within the normal range of human intake.

\section{Acknowledgements}

DK and ZY performed the regular dietary assessments and ensured compliance while carrying out the daily measurements of study parameters. JL supervised the daily conduct of the study supervised the database and assisted with data analysis. JR helped conceptualize the study and had overall supervisory responsibility for it. All authors read and approved the final manuscript.

\section{Conflicts of Interest}

JR's laboratory has received unrestricted grant funding to conduct research trials, and JR has received consulting fees from a variety of companies, organizations, publishers or trade associations that utilize, market or publish information about fructose, high fructose corn syrup or sucrose and, hence, have an ongoing interest in the metabolism and health effects of these sugars.

Dr. Rippe had full access to all of the data in this study and takes complete responsibility for the integrity of the data and accuracy of the data analysis. The other study authors report no competing interests.

\section{References}

[1] Hu, F.B. (2011) Globalization of Diabetes: The Role of Diet, Lifestyle, and Genes. Diabetes Care, 34, 1249-1257. http://dx.doi.org/10.2337/dc11-0442

[2] Shaw, J.E., Sicree, R.A. and Zimmet, P.Z. (2010) Global Estimates of the Prevalence of Diabetes for 2010 and 2030. Diabetes Research and Clinical Practice, 87, 4-14. http://dx.doi.org/10.1016/j.diabres.2009.10.007

[3] Danaei, G., Finucane, M.M., Lu, Y., Singh, G.M., Cowan, M.J., Paciorek, C.J., Lin, J.K., Farzadfar, F., Khang, Y.H., Stevens, G.A., Rao, M., Ali, M.K., Riley, L.M., Robinson, C.A. and Ezzati, M., on Behalf of the Global Burden of Metabolic Risk Factors of Chronic Diseases Collaborating Group (2011) National, Regional, and Global Trends in Fasting Plasma Glucose and Diabetes Prevalence since 1980: Systematic Analysis of Health Examination Surveys and Epidemiological Studies with 370 Country-Years and 2.7 Million Participants. Lancet, 378, 31-40. http://dx.doi.org/10.1016/S0140-6736(11)60679-X

[4] International Diabetes Federation (2014) IDF Diabetes Atlas. Epidemiology and Morbidity. In: International Diabetes Federation. www.idf.org

[5] Montonen, J., Jarvinen, R., Knekt, P., Heliovaara, M. and Reunanen, A. (2007) Consumption of Sweetened Beverages and Intakes of Fructose and Glucose Predict Type 2 Diabetes Occurrence. Journal of Nutrition, 137, 1447-1454.

[6] Schulze, M.B., Hoffmann, K., Manson, J.E., Willett, W.C., Meigs, J.B., Weikert, C., Heidemann, C., Colditz, G.A. and Hu, F.B. (2005) Dietary Pattern, Inflammation, and Incidence of Type 2 Diabetes in Women. American Journal of Clinical Nutrition, 82, 675-684.

[7] Le, K.A., Ith, M., Kreis, R., Faeh, D., Bortolotti, M., Tran, C., Boesch, C. and Tappy, L. (2009) Fructose Overconsumption Causes Dyslipidemia and Ectopic Lipid Deposition in Healthy Subjects with and without a Family History of Type 2 Diabetes. American Journal of Clinical Nutrition, 89, 1760-1765. http://dx.doi.org/10.3945/ajcn.2008.27336

[8] de Koning, L., Malik, V.S., Kellogg, M.D., Rimm, E.B., Willett, W.C. and Hu, F.B. (2012) Sweetened Beverage Con- 
sumption, Incident Coronary Heart Disease and Biomarkers of Risk in Men. Circulation, 125, 1735-1741. http://dx.doi.org/10.1161/CIRCULATIONAHA.111.067017

[9] Sluijs, I., Beulens, J.W.J., van der Schouw, Y.T., van der A, D.L., Buckland, G., Kuijsten, A., Schulze, M.B., Amiano, P., Ardanaz, E., Balkau, B., Boeing, H., Gavrila, D., Grote, V.A., Key, T.J., Li, K., Nilsson, P., Overvad, K., Palli, D., Panico, S., Quirós, J.R., Rolandsson, O., Roswall, N., Sacerdote, C., Sánchez, M.-J., Sieri, S., Slimani, N., Spijkerman, A.M.W., Tjønneland, A., Tumino, R., Sharp, S.J., Langenberg, C., Feskens, E.J.M., Forouhi, N.G., Riboli, E. and Wareham, N.J. (2013) Dietary Glycemic Index, Glycemic Load, and Digestible Carbohydrate Intake Are Not Associated with Risk of Type 2 Diabetes in Eight European Countries. Journal of Nutrition, 143, 93-99. http://dx.doi.org/10.3945/jn.112.165605

[10] The InterAct Consortium (2013) Consumption of Sweet Beverages and Type 2 Diabetes Incidence in European Adults: Results from EPIC-InterAct. Diabetologia, 56, 1520-1530. http://dx.doi.org/10.1007/s00125-013-2899-8

[11] Sanchez-Lozada, L.G., Le, M., Segal, M. and Johnson, R.J. (2008) How Safe Is Fructose for Persons with or without Diabetes? American Journal of Clinical Nutrition, 88, 1189-1190.

[12] Johnson, R.J., Segal, M.S., Sautin, Y., Nakagawa, T., Feig, D.I., Kang, D.H., Gersch, M.S., Benner, S. and SanchezLozada, L.G. (2007) Potential Role of Sugar (Fructose) in the Epidemic of Hypertension, Obesity and the Metabolic Syndrome, Diabetes, Kidney Disease, and Cardiovascular Disease. American Journal of Clinical Nutrition, 86, 899906.

[13] Bray, G.A. (2012) Fructose and Risk of Cardiometabolic Disease. Current Atherosclerosis Reports, 14, 570-578. http://dx.doi.org/10.1007/s11883-012-0276-6

[14] Basu, S., Yoffe, P., Hills, N. and Lustig, R.H. (2013) The Relationship of Sugar to Population-Level Diabetes Prevalence: An Econometric Analysis of Repeated Cross-Sectional Data. PLoS ONE, 8, e57873. http://dx.doi.org/10.1371/journal.pone.0057873

[15] Goran, M.I., Ulijaszek, S.J. and Ventura, E.E. (2013) High Fructose Corn Syrup and Diabetes Prevalence: A Global Perspective. Global Public Health, 8, 55-64. http://dx.doi.org/10.1080/17441692.2012.736257

[16] Mielke, J.G., Taghibiglou, C., Liu, L., Zhang, Y., Jia, Z., Adeli, K. and Wang, Y.T. (2005) A Biochemical and Functional Characterization of Diet-Induced Brain Insulin Resistance. Journal of Neurochemistry, 93, 1568-1578. http://dx.doi.org/10.1111/j.1471-4159.2005.03155.x

[17] Maiztegui, B., Borelli, M.I., Raschia, M.A., Del Zotto, H. and Gagliardino, J.J. (2009) Islet Adaptive Changes to Fructose-Induced Insulin Resistance: Beta-Cell Mass, Glucokinase, Glucose Metabolism, and Insulin Secretion. Journal of Endocrinology, 200, 139-149. http://dx.doi.org/10.1677/JOE-08-0386

[18] Rizkalla, S.W., Boillot, J., Tricottet, V., Fontvieille, A.M., Luo, J., Salzman, J.L., Camilleri, J.P. and Slama, G. (1993) Effects of Chronic Dietary Fructose with and without Copper Supplementation on Glycaemic Control, Adiposity, Insulin Binding to Adipocytes and Glomerular Basement Membrane Thickness in Normal Rats. British Journal of Nutrition, 70, 199-209. http://dx.doi.org/10.1079/BJN19930117

[19] Thorburn, A.W., Storlien, L.H., Jenkins, A.B., Khouri, S. and Kraegen, E.W. (1989) Fructose-Induced in Vivo Insulin Resistance and Elevated Plasma Triglyceride Levels in Rats. American Journal of Clinical Nutrition, 49, 1155-1163.

[20] Lewis, G.F., Uffelman, K., Naples, M., Szeto, L., Haidari, M. and Adeli, K. (2005) Intestinal Lipoprotein Overproduction, a Nearly Recognized Component of Insulin Resistance, Is Ameliorated by the Insulin Sensitizer Rosiglitazone: Studies in the Fructose-Fed Syrian Golden Hamster. Endocrinology, 146, 247-255. http://dx.doi.org/10.1210/en.2004-1143

[21] Pooranaperundevi, M., Sumiyabanu, M.S., Viswanathan, P., Sundarapandiyan, R. and Anuradha, C.V. (2010) Insulin Resistance Induced by High-Fructose Diet Potentiates Carbon Tetrachloride Hepatotoxicity. Toxicology and Industrial Health, 26, 89-104. http://dx.doi.org/10.1177/0748233709359273

[22] Stanhope, K.L., Schwarz, J.M., Keim, N.L., Griffen, S.C., Bremer, A.A., Graham, J.L., Hatcher, B., Cox, C.L., Dyachenko, A., Zhang, W., McGahan, J.P., Seibert, A., Krauss, R.M., Chiu, S., Schaefer, E.J., Ai, M., Otokozawa, S., Nakajima, K., Nakano, T., Beysen, C., Hellerstein, M.K., Berglund, L. and Havel, P.J. (2009) Consuming FructoseSweetened, Not Glucose-Sweetened, Beverages Increases Visceral Adiposity and Lipids and Decreases Insulin Sensitivity in Overweight/Obese Humans. Journal of Clinical Investigation, 119, 1322-1334. http://dx.doi.org/10.1172/JCI37385

[23] Hodge, A.M., English, D.R., O’Dea, K. and Giles, G.G. (2004) Glycemic Index and Dietary Fiber and the Risk of Type 2 Diabetes. Diabetes Care, 27, 2701-2706. http://dx.doi.org/10.2337/diacare.27.11.2701

[24] Janket, S.J., Manson, J.E., Sesso, H., Buring, J.E. and Liu, S. (2003) A Prospective Study of Sugar Intake and Risk of Type 2 Diabetes in Women. Diabetes Care, 26, 1008-1015. http://dx.doi.org/10.2337/diacare.26.4.1008

[25] Meyer, K.A., Kushi, L.H., Jacobs Jr., D.R., Slavin, J., Sellers, T.A. and Folsom, A.R. (2000) Carbohydrates, Dietary Fiber, and Incident Type 2 Diabetes in Older Women. American Journal of Clinical Nutrition, 71, 921-930. 
[26] Colditz, G.A., Manson, J.E., Stampfer, M.J., Rosner, B., Willett, W.C. and Speizer, F.E. (1992) Diet and Risk of Clinical Diabetes in Women. American Journal of Clinical Nutrition, 55, 1018-1023.

[27] Cozma, A.I., Sievenpiper, J.L., de Souza, R.J., Chiavaroli, L., Ha, V., Wang, D.D., Mirrahimi, A., Yu, M.E., Carleton, A.J., Di Buono, M., Jenkins, A.L., Leiter, L.A., Wolever, T.M.S., Beyene, J., Kendall, C.W.C. and Jenkins, D.J.A. (2012) Effect of Fructose on Glycemic Control in Diabetes: A Systematic Review and Meta-Analysis of Controlled Feeding Trials. Diabetes Care, 35, 1611-1620. http://dx.doi.org/10.2337/dc12-0073

[28] Cozma, A.I., Ha, V., de Souza, R.J. and Sievenpiper, J. (2014) Sweeteners and Diabetes. In: Rippe, J.M., Ed., Fructose, High Fructose Corn Syrup, Sucrose and Health, Springer Publishing, New York, 309-323. http://dx.doi.org/10.1007/978-1-4899-8077-9_19

[29] Johnson, R.K., Appel, L.J., Brands, M., Howard, B.V., Lefevre, M., Lustig, R.H., Sacks, F., Steffen, L.M. and WylieRosett, F., on Behalf of the American Heart Association Nutrition Committee of the Council on Nutrition, Physical Activity and Metabolism and the Council on Epidemiology and Prevention (2009) Dietary Sugars Intake and Cardiovascular Health: A Scientific Statement from the American Heart Association. Circulation, 120, 1011-1020. http://dx.doi.org/10.1161/CIRCULATIONAHA.109.192627

[30] World Health Organization (2008) The Global Burden of Disease: 2004 Update. Geneva.

[31] Scientific Advisory Committee on Nutrition (2014) Draft Carbohydrates and Health Report. 26 June-1 September 2014. http://www.sacn.gov.uk/

[32] Center for Nutrition Policy and Promotion (2010) Report of the Dietary Guidelines Advisory Committee on the Dietary Guidelines for Americans. US Department of Agriculture, Washington DC. http://www.nutriwatch.org/05Guidelines/dga_advisory_2010.pdf

[33] Institute of Medicine (2005) Dietary Reference Intakes for Energy, Carbohydrate, Fiber, Fat, Fatty Acids, Cholesterol, Protein and Amino Acids. Institute of Medicine of the National Academies.

[34] Marriott, B., Cole, N. and Lee, E. (2009) National Estimates of Dietary Fructose Intake Increased from 1977 to 2004 in the United States. Journal of Nutrition, 139, 1228S-1235S. http://dx.doi.org/10.3945/jn.108.098277

[35] Lowndes, J., Sinnett, S., Yu, Z. and Rippe, J. (2014) The Effects of Fructose-Containing Sugars on Weight, Body Composition and Cardiometabolic Risk Factors When Consumed at up to the 90th Percentile Population Consumption Level for Fructose. Nutrients, 6, 3153-3168. http://dx.doi.org/10.3390/nu6083153

[36] Mifflin, M.D., St. Jeor, S.T., Hill, L.A., Scott, B.J., Daugherty, S.A. and Koh, Y.O. (1990) A New Predictive Equation for Resting Energy Expenditure in Healthy Individuals. American Journal of Clinical Nutrition, 51, 241-247.

[37] Matthews, D.R., Hosker, J.P., Rudenski, A.S., Naylor, B.A., Treacher, D.F. and Turner, R.C. (1985) Homeostasis Model Assessment: Insulin Resistance and Beta-Cell Function from Fasting Plasma Glucose and Insulin Concentrations in Man. Diabetologia, 28, 412-419. http://dx.doi.org/10.1007/BF00280883

[38] Abdul-Ghani, M.A., Matsuda, M., Balas, B. and DeFronzo, R.A. (2007) Muscle and Liver Insulin Resistance Indexes Derived from the Oral Glucose Tolerance Test. Diabetes Care, 30, 89-94. http://dx.doi.org/10.2337/dc06-1519

[39] Matsuda, M. and DeFronzo, R.A. (1999) Insulin Sensitivity Indices Obtained from Oral Glucose Tolerance Testing: Comparison with the Euglycemic Insulin Clamp. Diabetes Care, 22, 1462-1470. http://dx.doi.org/10.2337/diacare.22.9.1462

[40] White, J.S. (2013) Challenging the Fructose Hypothesis: New Perspectives on Fructose Consumption and Metabolism. Advances in Nutrition, 4, 246-256. http://dx.doi.org/10.3945/an.112.003137

[41] Malik, V.S., Popkin, B.M., Bray, G.A., Despres, J.P., Willett, W.C. and Hu, F.B. (2010) Sugar-Sweetened Beverages and Risk of Metabolic Syndrome and Type 2 Diabetes: A Meta-Analysis. Diabetes Care, 33, 2477-2483. http://dx.doi.org/10.2337/dc10-1079

[42] Pan, A., Sun, Q., Bernstein, A.M., Schulze, M.B., Manson, J.E., Willett, W.C. and Hu, F.B. (2011) Red Meat Consumption and Risk of Type 2 Diabetes: 3 Cohorts of US Adults and an Updated Meta-Analysis. American Journal of Clinical Nutrition, 94, 1088-1096. http://dx.doi.org/10.3945/ajcn.111.018978

[43] Halton, T.L., Willett, W.C., Liu, S., Manson, J.E., Stampfer, M.J. and Hu, F.B. (2006) Potato and French Fry Consumption and Risk of Type 2 Diabetes in Women. American Journal of Clinical Nutrition, 83, 284-290.

[44] Barclay, A.W. and Brand-Miller, J. (2012) The Australian Paradox: A Substantial Decline in Sugars Intake over the Same Timeframe That Overweight and Obesity Have Increased. Nutrients, 3, 491-504. http://dx.doi.org/10.3390/nu3040491

[45] Welsh, J.A., Sharma, A.J., Grellinger, L. and Vos, M.B. (2011) Consumption of Added Sugars Is Decreasing in the United States. American Journal of Clinical Nutrition, 94, 726-734. http://dx.doi.org/10.3945/ajcn.111.018366

[46] Centers for Disease Control and Prevention (2011) Total Added Sugars, Have Not Resulted in a Decrease of Obesity or Diabetes in the US (Centers for Disease Control and Prevention 2011). http://www.cdc.gov/diabetes/statistics/slides/maps_diabetesobesity_trends.pdf 
[47] Sievenpiper, J.L., de Souza, R.J., Kendall, C.W. and Jenkins, D.J. (2011) Is Fructose a Story of Mice but Not Men? Journal of the American Dietetic Association, 111, 219-220. http://dx.doi.org/10.1016/j.jada.2010.12.001

[48] Hellerstein, M.K., Schwarz, J.M. and Neese, R.A. (1996) Regulation of Hepatic de Novo Lipogenesis in Humans. Annual Review of Nutrition, 16, 523-557. http://dx.doi.org/10.1146/annurev.nu.16.070196.002515

[49] Tappy, L. and Le, K.A. (2012) Does Fructose Consumption Contribute to Non-Alcoholic Fatty Liver Disease? Clinics and Research in Hepatology and Gastroenterology, 36, 554-560. http://dx.doi.org/10.1016/j.clinre.2012.06.005

[50] Sun, S.Z. and Empie, M.W. (2012) Fructose Metabolism in Humans: What Isotopic Tracer Studies Tell Us. Nutrition \& Metabolism, 9, 89. http://dx.doi.org/10.1186/1743-7075-9-89 
Scientific Research Publishing (SCIRP) is one of the largest Open Access journal publishers. It is currently publishing more than 200 open access, online, peer-reviewed journals covering a wide range of academic disciplines. SCIRP serves the worldwide academic communities and contributes to the progress and application of science with its publication.

Other selected journals from SCIRP are listed as below. Submit your manuscript to us via either submit@scirp.org or Online Submission Portal.
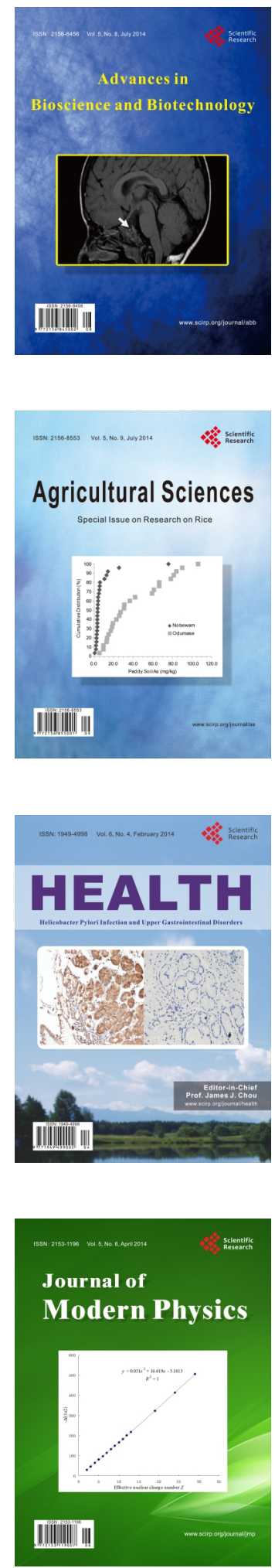
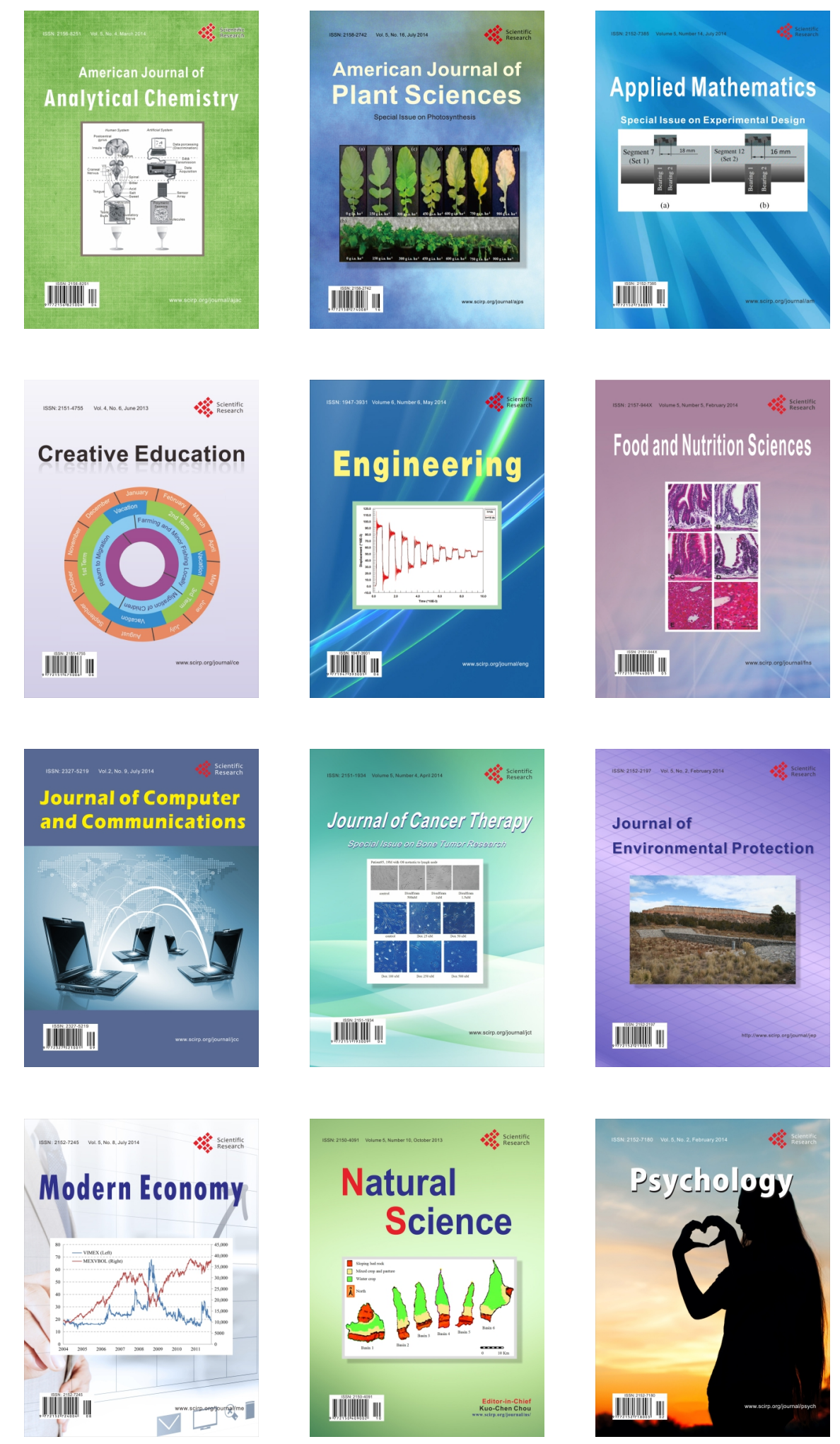